\title{
Surface Plasmon Resonance Enhanced Spontaneous Upconversion and Stimulated Emissions in Glass Ceramics Containing $\mathrm{Ba}_{2} \mathrm{LaF}_{7}$ Nanocrystals
}

\author{
Sai Li, ${ }^{1}$ Wei Lu, ${ }^{2}$ Qihua Yang, ${ }^{1}$ Dacheng Zhou, ${ }^{1,3}$ Jianbei Qiu, ${ }^{1,3}$ Xuhui Xu, ${ }^{1,3}$ and Xue Yu ${ }^{1,3}$ \\ ${ }^{1}$ College of Materials Science and Engineering, Kunming University of Science and Technology, Kunming 650093, China \\ ${ }^{2}$ University Research Facility in Materials Characterization and Device Fabrication, \\ The Hong Kong Polytechnic University, Hung Hom, Hong Kong \\ ${ }^{3}$ Key Laboratory of Advanced Materials of Yunnan Province, Kunming 650093, China
}

Correspondence should be addressed to Xue Yu; yuyu6593@126.com

Received 19 June 2017; Accepted 10 August 2017; Published 13 September 2017

Academic Editor: Zaiquan Xu

Copyright (C) 2017 Sai Li et al. This is an open access article distributed under the Creative Commons Attribution License, which permits unrestricted use, distribution, and reproduction in any medium, provided the original work is properly cited.

\begin{abstract}
Glass ceramics containing $\mathrm{Yb}^{3+}, \mathrm{Er}^{3+}$ codoped $\mathrm{Ba}_{2} \mathrm{LaF}_{7}$ nanocrystals were fabricated via melt quenching method and the subsequent heating treatment. The formation of $\mathrm{Ba}_{2} \mathrm{LaF}_{7}$ nanocrystals in the glass ceramics was confirmed by X-ray diffraction (XRD) and transmission electron microscope (TEM). The spontaneous upconversion (UC) emission and the stimulated counterpart as a random lasing action of $\mathrm{Er}^{3+}$, which were related to the characteristic transitions of $\mathrm{Er}^{3+}$ ions, were achieved in the $\mathrm{Yb}^{3+}, \mathrm{Er}^{3+}$ doped $\mathrm{Ba}_{2} \mathrm{LaF}_{7}$ nanocrystals embedded glass ceramic hybrid. Furthermore, the absorption spectra verified the surface plasmon resonance (SPR) band of Ag, which precipitated from the matrix glasses as Ag nanoparticles (NPs). By incorporating Ag NPs in the glass ceramic hybrid, spontaneous UC emission intensity of $\mathrm{Er}^{3+}$ in visible region was significantly enhanced, while the threshold of the random lasing was decreased from 480 to $350 \mathrm{~nJ} / \mathrm{cm}^{2}$.
\end{abstract}

\section{Introduction}

The integration of novel luminescent nanometer materials into glassy matrix can bring about new and promising optical hybrid materials and photonic devices in recent years [1]. Great enhancement of optical emission efficiency was realized in fluorosilicate glasses by the growth of the lanthanide doped fluoride nanocrystals embedded in the glass matrix [2]. Lanthanide-containing UC nanocrystals have become distinct candidates for biomedical imaging, anticounterfeiting, biological sensing, solar energy management, data storage, and 3D volumetric displays, which enable higherenergy emissions in the ultraviolet to visible spectral range by upconverting two or more near-infrared excitation photons $[3,4]$. Once lanthanide ions are located inside the fluoride nanocrystals, they will be in the low phonon energy environment. So the multiphonon relaxation rates can be significantly reduced from some excited states $[5,6]$. Oxyfluoride glass ceramics combine the favorable properties of fluoride crystal (low refractive index and phonon energy) and the oxide glasses (high chemical stability and large solubility of rare-earth (RE) ions). Thus, oxyfluoride glass ceramics have potential applications in the fields of luminescence applications and laser [7].

$\mathrm{Er}^{3+}$-doped UC materials are popular due to their high luminescence quenching concentration compared to other rare-earth ions. In addition, $\mathrm{Er}^{3+}$ ions have a large spectral overlap with $\mathrm{Yb}^{3+}$, and $\mathrm{Yb}^{3+}$ ions can absorb the photons of $980 \mathrm{~nm}$ effectively. Therefore, $\mathrm{Yb}^{3+}$ and $\mathrm{Er}^{3+}$ codoping materials can enhance the UC efficiency through the energy transfer, which demonstrated that the $\mathrm{Yb}^{3+}$ and $\mathrm{Er}^{3+}$ codoping materials exhibit excellent luminescent properties. SPR arises by the collective oscillation of electrons on the metal nanoparticles, which can have either beneficial or deleterious effect depending on the position of the SPR peak and the distance of the luminophore from the metal surface $[8,9]$. Recently, SPR has been energetically used to improve the emission efficiency of luminescent materials and devices. 




(a)

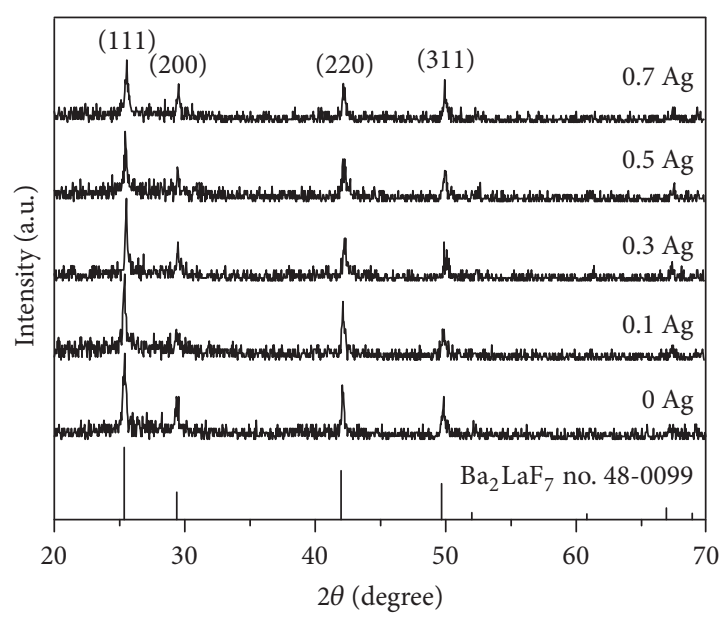

(b)

FIGURE 1: (a) DSC of $0.5 \mathrm{Ag}$ sample. (b) XRD patterns of glass ceramic samples with different Ag concentration.

For example, the photoluminescence (PL) intensity in the dye-doped polymers [10], CdSe quantum dots [11], Si quantum dots [12], ZnO films [13, 14], and InGaN quantum wells [15] was improved significantly due to the SPR excitation. In contrast to the continuous efforts to spontaneous emissions, little knowledge has been known in the stimulated counterparts. However, the incorporation of metallic nanostructures into optical gain media may lead to a breakthrough of laser devices, that is, to beat the diffraction limit with regard to both of the physical dimension and optical mode size [16]. Besides, the enhanced local field occurring in hot spots is particularly important to trigger low threshold lasing resonance because it can locally enhance the pump rate of gain media $[7,17]$.

Thus, in this work, $\mathrm{Yb}^{3+}, \mathrm{Er}^{3+}$-doped $\mathrm{Ba}_{2} \mathrm{LaF}_{7}$ glass ceramic as an effective UC material was synthesized via conventional melt quenching technique and the subsequently heat treatment. Besides, a nanosecond laser pumped random lasing action has been achieved in the silicate oxyfluoride glass ceramics containing $\mathrm{Ba}_{2} \mathrm{LaF}_{7}$ nanocrystals. By incorporating Ag NPs, spontaneous UC emission intensity of $\mathrm{Er}^{3+}$ in visible region was drastically enhanced, while the threshold of the random lasing decreased significantly from 450 to $350 \mathrm{~nJ} / \mathrm{cm}^{2}$.

\section{Experimental}

The glass ceramic samples were prepared according to the following composition (mol\%): $45 \mathrm{SiO}_{2}-15 \mathrm{Al}_{2} \mathrm{O}_{3}-12 \mathrm{Na}_{2} \mathrm{CO}_{3}$ $20 \mathrm{BaF}_{2}-6.5 \mathrm{LaF}_{3}-1 \mathrm{YbF}_{3}-0.5 \mathrm{ErF}_{3}$ doped with $x$ wt $\%$ of $\mathrm{Ag}_{2} \mathrm{O}$ by the conventional melt quenching technique $(x=0$, $0.1,0.3,0.5,0.7$ ), denoted as $0 \mathrm{Ag}, 0.1 \mathrm{Ag}, 0.3 \mathrm{Ag}, 0.5$ $\mathrm{Ag}$, and $0.7 \mathrm{Ag}$. About $10 \mathrm{~g}$ of original material was fully mixed and then melted in an air atmosphere at $1500^{\circ} \mathrm{C}$ for $45 \mathrm{~min}$. The crucible was covered with an alumina cap to avoid volatilization loss. The molten glass was cast into a carbon plate maintained at about $300^{\circ} \mathrm{C}$. The glass samples were annealed at $500^{\circ} \mathrm{C}$ for $8 \mathrm{~h}$ to avoid internal stress. The obtained glass was thermally treated at $670^{\circ} \mathrm{C}$ for $2 \mathrm{~h}$ to induce crystallization.

XRD was performed using a D8 Focus diffractometer (Bruker) with $\mathrm{Cu}-\mathrm{K} \alpha$ radiation $(\lambda=0.15405 \mathrm{~nm})$ in the $2 \theta$ range from $20^{\circ}$ to $70^{\circ}$. The UC photoluminescence spectra in the wavelength range of 450 to $700 \mathrm{~nm}$ were recorded by using a HITACHIF-7000. Fluorescence spectrophotometer was under the excitation of $980 \mathrm{~nm}$ laser diode with the power of $2 \mathrm{~W}$. The absorption spectra were recorded in the wavelength range from 350 to $600 \mathrm{~nm}$ using a Model U4100 Spectrophotometer. To detect the nucleation and growth of Ag NPs, a TEM (JEM-2100) operating at an accelerating voltage of $200 \mathrm{kV}$ was used. For the laser measurement, a Continuum Panther EX optical parametric oscillator and a $355 \mathrm{~nm}$ frequency-tripled Continuum Powerlite DLS 9010 Q-switched Nd: YAG laser were used to generate $980 \mathrm{~nm}$ pump pulses of width and repetition rate of $\approx 6 \mathrm{~ns}$ and $10 \mathrm{~Hz}$, respectively. The laser beam of diameter equal to $8 \mathrm{~mm}$ was focused on the surface of the glass ceramics by a cylindrical lens with focal length of $100 \mathrm{~mm}$. Light emitted from the side of the glass was recorded by an optical fiber connected to a spectrum analyzer (Oriel MS257 monochromator with spectral resolution $\approx 0.1 \mathrm{~nm}$ ). The sample was placed in a temperature regulating chamber with $\mathrm{N}_{2}$ (Linkam DSC 600 stage system). For the sample under pulse excitation, the temperature rise was negligible due to the influence of the optical pumping. However, for continuous wave excitation samples, the average temperature of the sample must be offset $18 \mathrm{~K}$.

\section{Results and Discussion}

Figure 1(a) shows the differential scanning calorimetry (DSC) spectrum of the $0.5 \mathrm{Ag}$ sample. As can be seen in this figure, there are three temperature parameters: the glass transition temperature $\left(T_{g}\right)$ located in the vicinity of $574^{\circ} \mathrm{C}$ and temperature of two crystallization peaks $\left(T_{c 1}, T_{c 2}\right)$ located at the vicinity of $630^{\circ} \mathrm{C}$ and $745^{\circ} \mathrm{C}$. According to the 


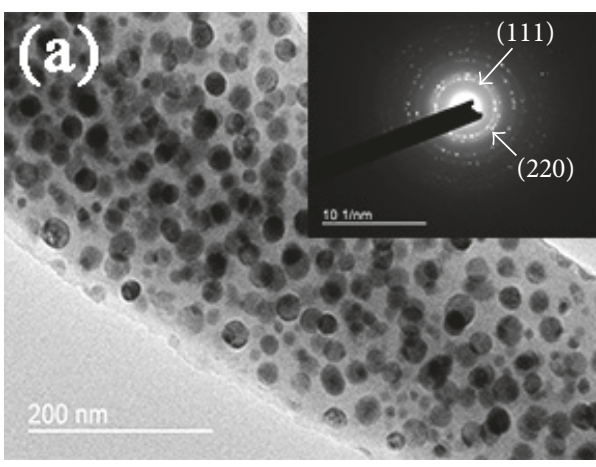

(a)



(c)

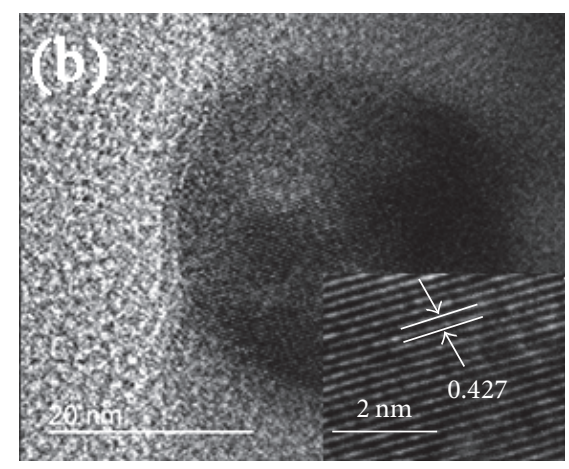

(b)

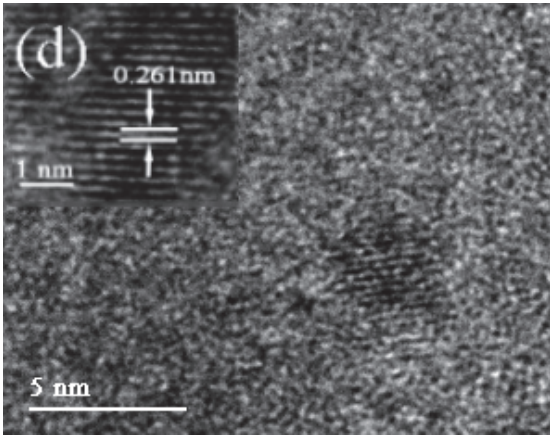

(d)

FIgURE 2: (a) TEM micrograph of 0 Ag sample: the inset is the SAED pattern of the 0 Ag sample. (b) HR-TEM image of 0 Ag sample: the inset is the enlargement of HR-TEM image of the corresponding sample. (c) TEM micrograph of $0.5 \mathrm{Ag}$ sample. (d) HR-TEM image of 0.5 Ag sample: the inset is the enlargement of HR-TEM image of the corresponding sample.

differential thermal analysis (DTA) results analysis, in this study, all the prepared glasses were heat-treated at $670^{\circ} \mathrm{C}$ for $2 \mathrm{~h}$ to precipitate nanocrystals. Figure 1(b) displays the XRD patterns of the samples by modulating the Ag concentration, respectively. All the diffraction peaks of the samples are in good agreement with hexagonal $\mathrm{Ba}_{2} \mathrm{LaF}_{7}$ (the standard JCPDS 48-0099). No second phase is detected in the XRD pattern, revealing that the high purity cubic phase of $\mathrm{Ba}_{2} \mathrm{LaF}_{7}$ has been fabricated.

The TEM micrograph of the $0 \mathrm{Ag}$ sample in Figure 2(a) demonstrates that $\mathrm{Ba}_{2} \mathrm{LaF}_{7}$ nanocrystals with the diameter of 7-12 nm distribute homogeneously among the glass matrix. HR-TEM image of Figure 2(b) shows the presence of clear and resolved lattice fringes of $0 \mathrm{Ag}$ sample. The inset in Figure 2(b) is the enlargement of HR-TEM image of the corresponding sample. As shown in the inset of Figure 2(b), the interplanar distance between the adjacent fringes is determined to be $0.427 \mathrm{~nm}$, which matches well, respectively, with those of the (111) plane of the cubic $\mathrm{Ba}_{2} \mathrm{LaF}_{7}$. The TEM image of the $0.5 \mathrm{Ag}$ sample is shown in Figure 2(c), indicating the presence of near-spherical NPs distributed homogeneously in the glass matrix with the particle size of about 2 to $4 \mathrm{~nm}$. Figure 2(d) is the HR-TEM image of $0.5 \mathrm{Ag}$ sample and the enlargement of HR-TEM image of the corresponding (the inset of Figure 2(d)). It shows that the interplanar distance between the adjacent fringes is determined to be $0.261 \mathrm{~nm}$ ascribed to the (200) planes of Ag. Thus, it is unambiguous evidence that Ag NPs are randomly distributed in the glass matrix.

Figure 3(a) shows the UC photoluminescence spectra of $0 \mathrm{Ag}, 0.1 \mathrm{Ag}, 0.3 \mathrm{Ag}, 0.5 \mathrm{Ag}$, and $0.7 \mathrm{Ag}$ samples pumped by $980 \mathrm{~nm}$ with $60 \mathrm{~W} / \mathrm{cm}^{2}$ excitation density. The characteristic green $(540 \mathrm{~nm})$ and red $(658 \mathrm{~nm})$ emissions, corresponding to ${ }^{4} \mathrm{~S}_{3 / 2} \rightarrow{ }^{4} \mathrm{I}_{15 / 2}$ and ${ }^{4} \mathrm{~F}_{9 / 2} \rightarrow{ }^{4} \mathrm{I}_{15 / 2}$ transitions of $\mathrm{Er}^{3+}$, respectively, are simultaneously observed. The UC emission intensity is greatly improved with increasing concentration of $\mathrm{Ag}_{2} \mathrm{O}$, and the maximum enhancement is realized when the concentration of $\mathrm{Ag}_{2} \mathrm{O}$ is up to $0.5 \mathrm{wt} \%$. Then, the UC emission intensity decreases with further increase of $\mathrm{Ag}_{2} \mathrm{O}$ concentrations. The inset exhibits the absorption spectra of the $0 \mathrm{Ag}, 0.1 \mathrm{Ag}, 0.3 \mathrm{Ag}, 0.5 \mathrm{Ag}$, and $0.7 \mathrm{Ag}$ samples. Absorption bands attributed to $4 \mathrm{f}-4 \mathrm{f}$ transitions of $\mathrm{Er}^{3+}$ ions corresponding to transitions starting from the ground state to the excited states are observed. As shown in the inset, the absorption spectra of the sample with $\mathrm{Ag}_{2} \mathrm{O}$ show a distinctive band centered at $420 \mathrm{~nm}$ that is attributed to the SPR associated with the Ag NPs [18]. The primary reason for such fluorescence intensification of RE ions which is attributed to a local field enhancement induced by SPR of metal NPs has been accepted [19-23].

In order to investigate the dependence of the UC emission intensities on the $\mathrm{Ag}_{2} \mathrm{O}$ concentrations in detail, the emission decay curves of the ${ }^{4} \mathrm{~S}_{3 / 2} \rightarrow{ }^{4} \mathrm{I}_{15 / 2}$ transitions of $\mathrm{Er}^{3+}$ in the series of Ag doped samples were measured under the $980 \mathrm{~nm}$ 


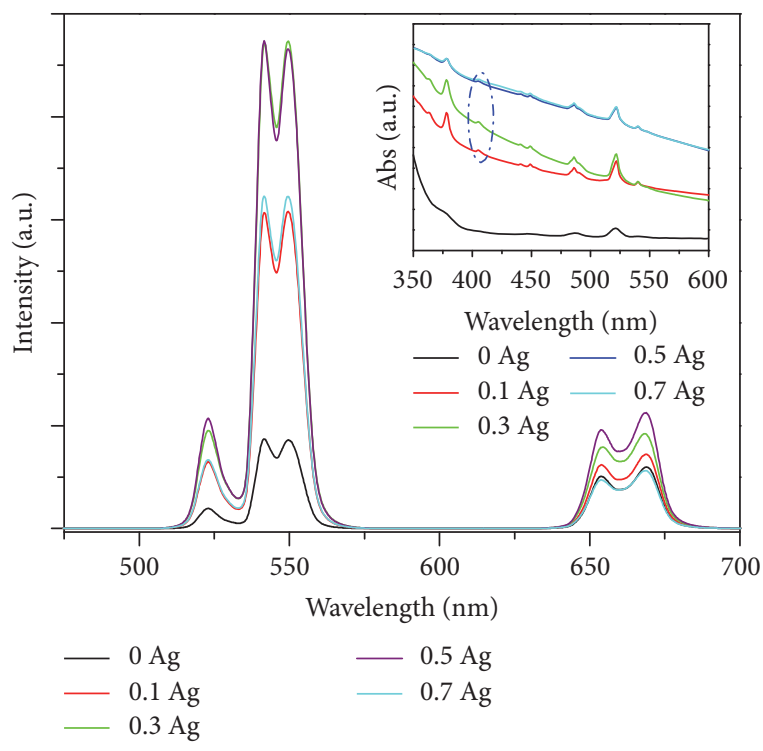

(a)

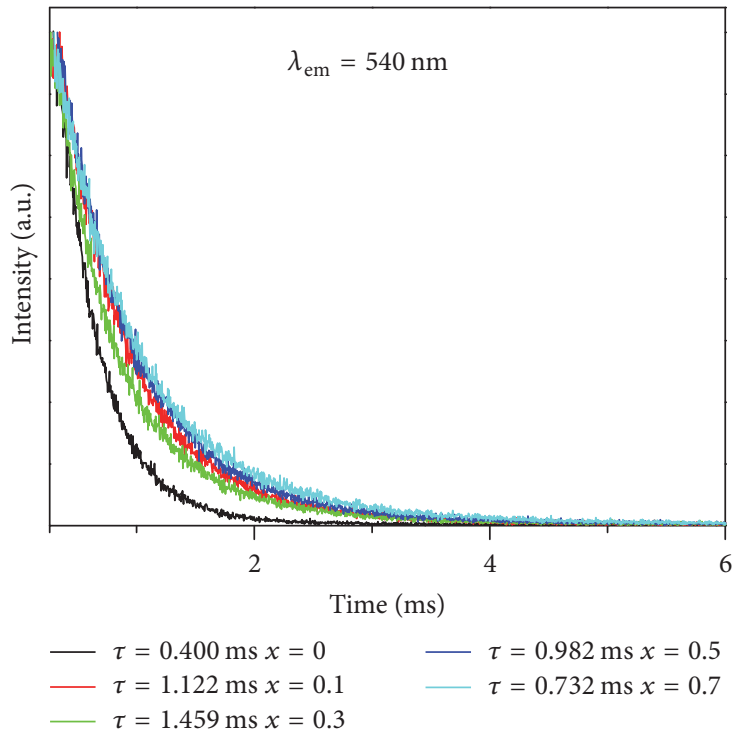

(b)

FIGURE 3: (a) UC luminescence spectra of samples with different Ag concentration under the excitation of $980 \mathrm{~nm}$ laser diode: the inset is absorption spectra of samples by modulating the Ag concentration. (b) Room temperature luminescence decay curves of ${ }^{4} \mathrm{~S}_{3 / 2} \rightarrow{ }^{4} \mathrm{I}_{15 / 2}\left(\mathrm{Er}^{3+}\right)$ transition of the $0 \mathrm{Ag}, 0.1 \mathrm{Ag}, 0.3 \mathrm{Ag}, 0.5 \mathrm{Ag}$, and $0.7 \mathrm{Ag}$ samples.

excitation, as displayed in Figure 3(b). The effective experimental lifetime can be evaluated as follows:

$$
\tau_{\text {eff }}=\frac{\int[I(t) * t * d t]}{\int[I(t) * d t]},
$$

where $I(t)$ represents the luminescence intensity at time $t$ after the cut-off of the excitation light. The lifetime of the transitions of ${ }^{4} \mathrm{~S}_{3 / 2} \rightarrow{ }^{4} \mathrm{I}_{15 / 2}$ is determined to be $0.400,1.122$, $1.459,0.982$, and $0.732 \mathrm{~ms}$ in the $0 \mathrm{Ag}, 0.1 \mathrm{Ag}, 0.3 \mathrm{Ag}, 0.5$ $\mathrm{Ag}$, and $0.7 \mathrm{Ag}$ samples, respectively. The lifetime decreases after the first increase, and the variation tendency agrees well with the change of UC luminescence intensities of green emission. The lifetime result is an evidence of an accelerating energy transfer from $\mathrm{Yb}^{3+}$ to $\mathrm{Er}^{3+}$ with increasing Ag NPs content $[24,25]$, which indicates that some energy transfer from fluorescent Ag NPs to $\mathrm{Er}^{3+}$ cannot be totally ignored.

Interestingly, microcavities can be realized by randomly embedding $\mathrm{Ba}_{2} \mathrm{LaF}_{7}: \mathrm{Yb}^{3+}, \mathrm{Er}^{3+}$ nanocrystals inside the glass and random lasing action can be achieved in the glass ceramic. The optically pumped spectra of $0.5 \mathrm{Ag}$ sample were collected under the $980 \mathrm{~nm}$ nanosecond laser beam; it was found that the Ag NPs decorated glass ceramics containing $\mathrm{Ba}_{2} \mathrm{LaF}_{7}$ nanocrystals exhibit a similar optically pumped random lasing characteristic as the corresponding glass ceramics without Ag. Figure 4(a) shows the lasing characteristics of the glass ceramics with the decoration of Ag NPs under different $980 \mathrm{~nm}$ pulsed excitation power at room temperature. As the pump energy exceeds an excitation threshold, $P_{\text {th }}$, of $385 \mathrm{~nJ} / \mathrm{cm}^{2}$ (i.e., kink of the light-light curve as shown in Figure 4(b)), one sharp peak emerges from the emission spectrum. In addition, further increase of the excitation intensity increases the number of sharp peaks. In this case, the sharp peaks represent the formation of closedloop paths for light (i.e., the realization of microcavities due to the coherent optical feedback from the Ag NPs). Figure 4(b) provides a direct proof of the central role of local field enhancement in the emergence of low threshold lasing resonance, and the threshold of the lasing decreased from 480 to $350 \mathrm{~nJ} / \mathrm{cm}^{2}$ with decorating of Ag NPs. It can be safe to say that the enhanced local field occurring in hot spots is particularly important to trigger low threshold lasing resonance since it can locally enhance the pump rate of gain media $[26,27]$. The corresponding plot of Fourier transform spectrum, as shown in Figure 4(c), exhibits periodic features, indicating the formation of closed-loop paths, and the roundtrip cavity length of the random modes inside the glass hybrid is ca. $9.81 \mu \mathrm{m}$. The inset of Figure 4(a) is the photograph of the $0.5 \mathrm{Ag}$ under the excitation of $980 \mathrm{~nm}$ nanosecond laser. It is clearly seen that a collimated output beam is emitted from one of the edge facets from the glass. The green spot projected behind a lens represents an output beam of lasing. This indicates that the output beam is highly directional and spatially coherent at a particular direction.

\section{Conclusions}

The spontaneous UC emissions intensity of $\mathrm{Er}^{3+}$ is drastically improved with the Ag NPs emerged in $\mathrm{Ba}_{2} \mathrm{LaF}_{7}$ glass ceramic for the contribution of the SPR and some of the energy transfer from $\mathrm{Ag}$ NPs to $\mathrm{Er}^{3+}$. Meanwhile, the stimulated emission as a random lasing action is achieved in this hybrid material. It is found that the incorporation of Ag NPs is advantageous in reducing the threshold of the lasing action. Therefore, the new class of hybrid glasses allows for fiberbased devices to be developed for photonic applications or 


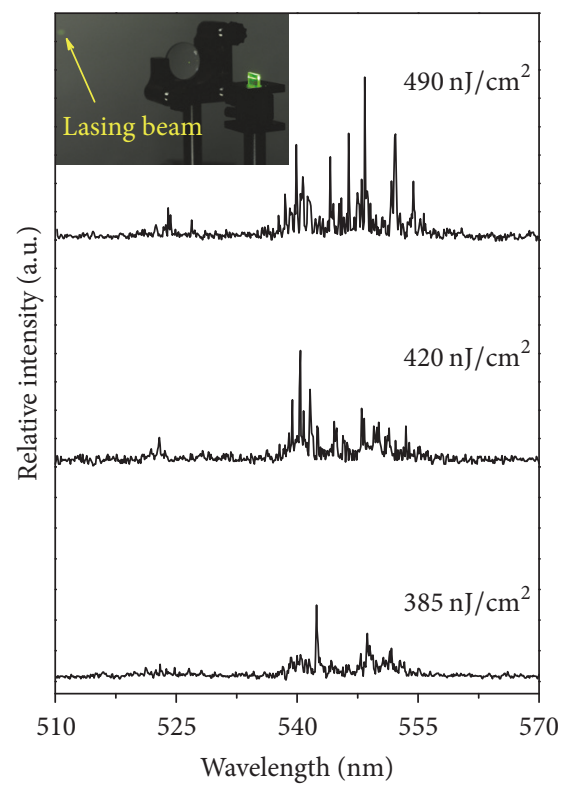

(a)

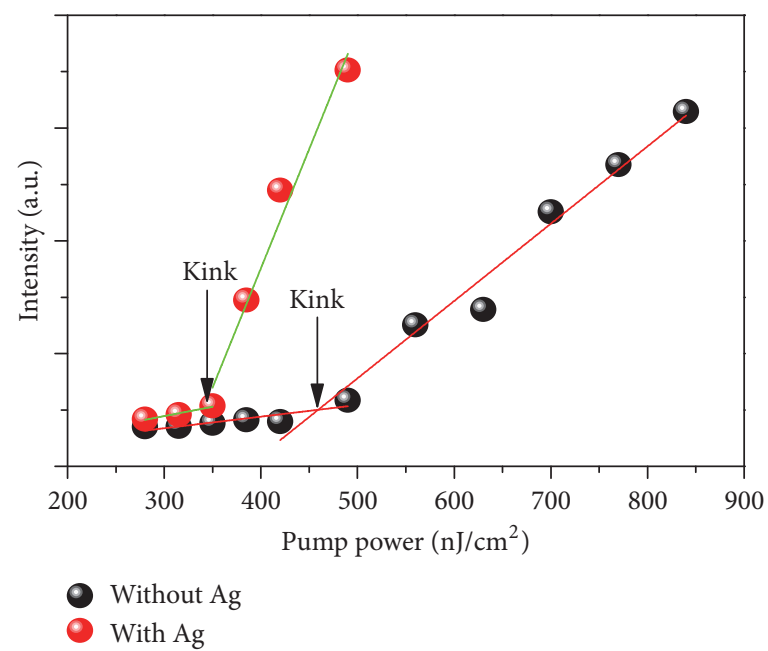

(b)

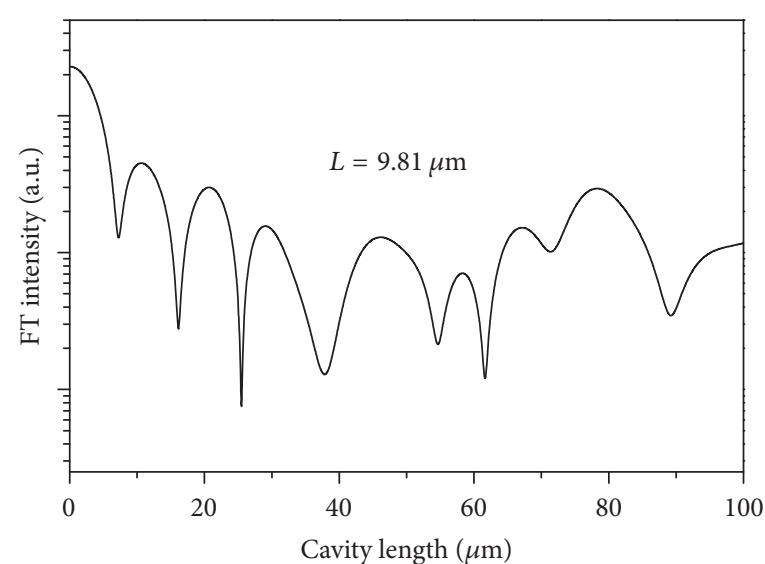

(c)

Figure 4: (a) Emission spectra of $0.5 \mathrm{Ag}$ sample under different pump intensity of $980 \mathrm{~nm}$ nanosecond lasers: the inset is the photograph of $0.5 \mathrm{Ag}$ sample under excitation of $980 \mathrm{~nm}$ nanosecond. (b) Integrated emission intensity of $0 \mathrm{Ag}$ and $0.5 \mathrm{Ag}$ samples versus pumping energy density. (c) Plot of Fourier transform (FT) patterns of the lasing spectra of the $0.5 \mathrm{Ag}$ sample.

as a useful tool for tailoring light-nanoparticles interactions study.

\section{Conflicts of Interest}

The authors declare that they have no conflicts of interest.

\section{Acknowledgments}

This work was financially supported by the National Nature Science Foundation of China (61565009, 61308091), the Foundation of Natural Science of Yunnan Province (2016FB088), the Young Talents Support Program of Faculty of Materials Science and Engineering, Kunming University of Science and Technology (14078342), and the Postdoctoral Science Foundation of China (2013M540720).

\section{References}

[1] J. Zhao, X. Zheng, E. P. Schartner et al., "Upconversion nanocrystal-doped glass: a new paradigm for photonic materials," Advanced Optical Materials, vol. 4, no. 10, pp. 1507-1517, 2016.

[2] J. Zhao, R. Ma, X. Chen et al., "From phase separation to nanocrystallization in fluorosilicate glasses: structural design of highly luminescent glass-ceramics," Journal of Physical Chemistry C, vol. 120, no. 31, pp. 17726-17732, 2016.

[3] D. Chen, Y. Wang, Y. Yu, F. Liu, and P. Huang, "Sensitized thulium ultraviolet upconversion luminescence in $\mathrm{Tm}^{3+} / \mathrm{Yb}^{3+} / \mathrm{Nd}^{3+}$ 
triply doped nanoglass ceramics," Optics Letters, vol. 32, no. 21, pp. 3068-3070, 2007.

[4] D. Chen, Y. Wang, N. Yu, P. Huang, and F. Weng, "Near-infrared quantum cutting in transparent nanostructured glass ceramics," Optics Letters, vol. 33, no. 16, pp. 1884-1886, 2008.

[5] G. A. Kumar, C. W. Chen, J. Ballato, and R. E. Riman, "Optical characterization of infrared emitting rare-earth-doped fluoride nanocrystals and their transparent nanocomposites," Chemistry of Materials, vol. 19, no. 6, pp. 1523-1528, 2007.

[6] D. Chen, Y. Yu, P. Huang, and Y. Wang, "Nanocrystallization of lanthanide trifluoride in an aluminosilicate glass matrix: dimorphism and rare earth partition," CrystEngComm, vol. 11, no. 8, pp. 1686-1690, 2009.

[7] X. Xu, W. Zhang, D. Yang, W. Lu, J. Qiu, and S. F. Yu, "Phononassisted population inversion in lanthanide-doped upconversion ba2laf7nanocrystals in glass-ceramics," Advanced Materials, vol. 28, no. 36, pp. 8045-8050, 2016.

[8] P. Bharadwaj, B. Deutsch, and L. Novotny, "Optical antennas," Advances in Optics and Photonics, vol. 1, no. 3, pp. 438-483, 2009.

[9] S. Chowdhury, V. R. Bhethanabotla, and R. Sen, "Silver-copper alloy nanoparticles for metal enhanced luminescence," Applied Physics Letters, vol. 95, no. 13, Article ID 131115, 2009.

[10] D. G. Zhang, X.-C. Yuan, and J. Teng, "Surface plasmon-coupled emission on metallic film coated with dye-doped polymer nanogratings," Applied Physics Letters, vol. 97, no. 23, Article ID 231117, 2010.

[11] N. A. Harun, M. J. Benning, B. R. Horrocks, and D. A. Fulton, "Gold nanoparticle-enhanced luminescence of silicon quantum dots co-encapsulated in polymer nanoparticles," Nanoscale, vol. 5, no. 9, pp. 3817-3827, 2013.

[12] F. Nan, Z.-Q. Cheng, Y.-L. Wang et al., "Manipulating nonlinear emission and cooperative effect of CdSe/ZnS quantum dots by coupling to a silver nanorod complex cavity," Scientific Reports, vol. 4, article no. 4839, 2014.

[13] G. W. Shu, C. H. Chiu, L. T. Huang et al., "Efficient energy transfer from InGaN quantum wells to Ag nanoparticles," Physical Chemistry Chemical Physics, vol. 15, no. 10, pp. 3618-3622, 2013.

[14] A. P. Abiyasa, S. F. Yu, S. P. Lau, E. S. P. Leong, and H. Y. Yang, "Enhancement of ultraviolet lasing from Ag-coated highly disordered $\mathrm{ZnO}$ films by surface-plasmon resonance," Applied Physics Letters, vol. 90, no. 23, Article ID 231106, 2007.

[15] X. Li, Y. Zhang, and X. Ren, "Effects of localized surface plasmons on the photoluminescence properties of Au-coated $\mathrm{ZnO}$ films," Optics Express, vol. 17, no. 11, pp. 8735-8740, 2009.

[16] O. Popov, A. Zilbershtein, and D. Davidov, "Random lasing from dye-gold nanoparticles in polymer films: Enhanced gain at the surface-plasmon-resonance wavelength," Applied Physics Letters, vol. 89, no. 19, Article ID 191116, 2006.

[17] Q. Qiao, C.-X. Shan, J. Zheng et al., "Surface plasmon enhanced electrically pumped random lasers," Nanoscale, vol. 5, no. 2, pp. 513-517, 2013.

[18] P. Piasecki, A. Piasecki, Z. Pan, R. Mu, and S. H. Morgan, "Formation of $\mathrm{Ag}$ nanoparticles and enhancement of $\mathrm{Tb}^{3+}$ luminescence in $\mathrm{Tb}$ and $\mathrm{Ag}$ co-doped lithium-lanthanumaluminosilicate glass," Journal of Nanophotonics, vol. 4, no. 1, Article ID 043522, 2010.

[19] T. Som and B. Karmakar, "Nanosilver enhanced upconversion fluorescence of erbium ions in $\mathrm{Er}^{3+}$ : Ag-antimony glass nanocomposites," Journal of Applied Physics, vol. 105, no. 1, Article ID 013102, 2009.
[20] W. L. Barnes, A. Dereux, and T. W. Ebbesen, "Surface plasmon subwavelength optics," Nature, vol. 424, no. 6950, pp. 824-830, 2003.

[21] C. D. Geddes and J. R. Lakowicz, "Metal-enhanced fluorescence," Journal of Fluorescence, vol. 12, no. 2, pp. 121-129, 2002.

[22] K.-H. Su, Q.-H. Wei, X. Zhang, J. J. Mock, D. R. Smith, and S. Schultz, "Interparticle coupling effects on plasmon resonances of nanogold particles," Nano Letters, vol. 3, no. 8, pp. 1087-1090, 2003.

[23] A. Bouhelier, "Field-enhanced scanning near-field optical microscopy," Microscopy Research and Technique, vol. 69, no. 7, pp. 563-579, 2006.

[24] X. Zhang, L. Zhou, Q. Pang, and M. Gong, "Novel broadband excited and linear red-emitting $\mathrm{Ba} 2 \mathrm{Y}\left(\mathrm{BO}_{3}\right)_{2} \mathrm{Cl}: \mathrm{Ce}^{3+}, \mathrm{Tb}^{3+}$, $\mathrm{Eu}^{3+}$ phosphor: luminescence and energy transfer," Journal of the American Ceramic Society, vol. 97, no. 7, pp. 2124-2129, 2014.

[25] L.-L. Wang, Q.-L. Wang, X.-Y. Xu et al., "Energy transfer from $\mathrm{Bi}^{3+}$ to $\mathrm{Eu}^{3+}$ triggers exceptional long-wavelength excitation band in $\mathrm{ZnWO}_{4}: \mathrm{Bi}^{3+}, \mathrm{Eu}^{3+}$ phosphors," Journal of Materials Chemistry C, vol. 1, no. 48, pp. 8033-8040, 2013.

[26] X. Xu, W. Zhang, L. Jin, J. Qiu, and S. F. Yu, "Random lasing in $\mathrm{Eu}^{3+}$ doped borate glass-ceramic embedded with Ag nanoparticles under direct three-photon excitation," Nanoscale, vol. 7, no. 39, pp. 16246-16250, 2015.

[27] X. Meng, K. Fujita, S. Murai, T. Matoba, and K. Tanaka, "Plasmonically controlled lasing resonance with metallic-dielectric core-shell nanoparticles," Nano Letters, vol. 11, no. 3, pp. 13741378, 2011. 

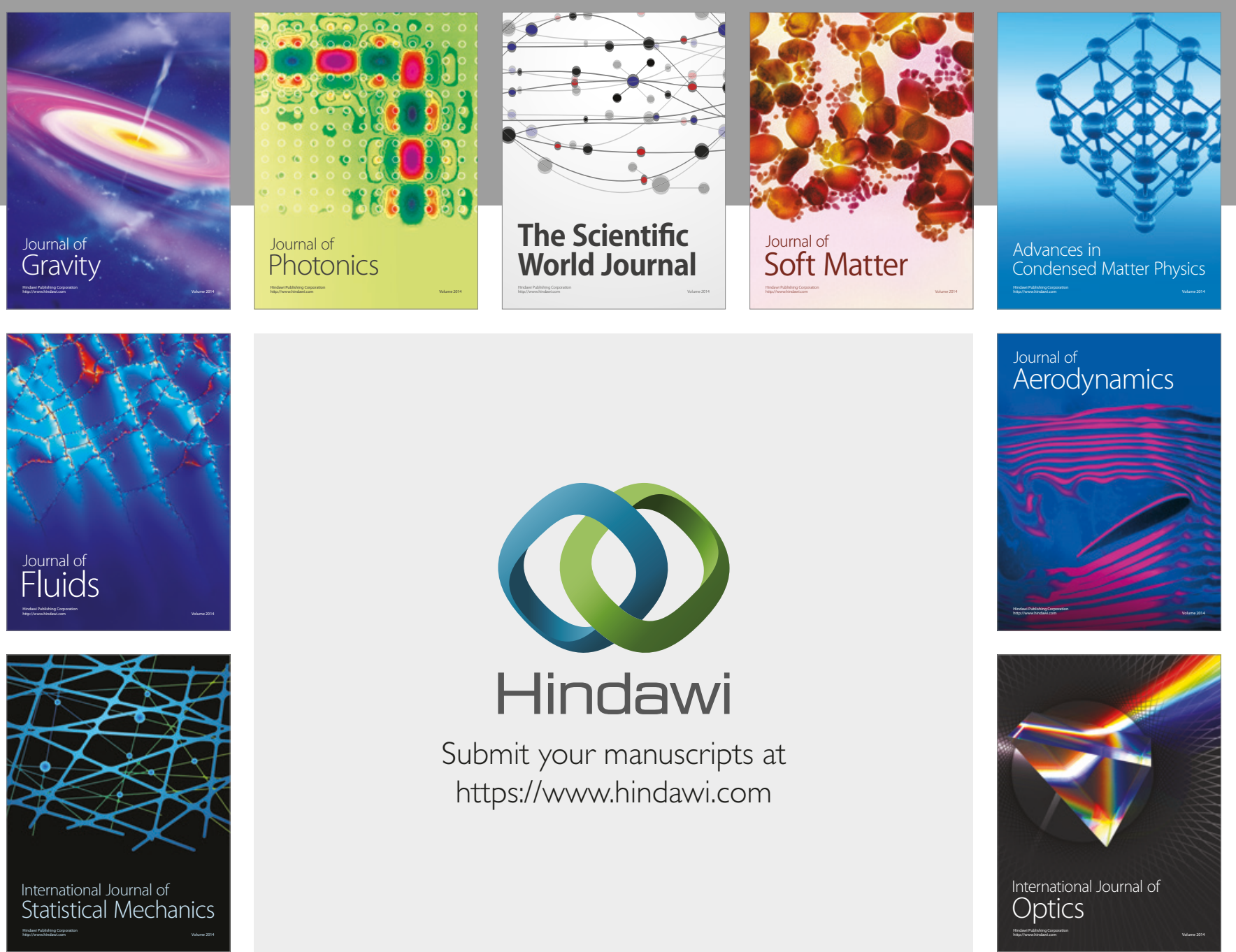

Submit your manuscripts at

https://www.hindawi.com
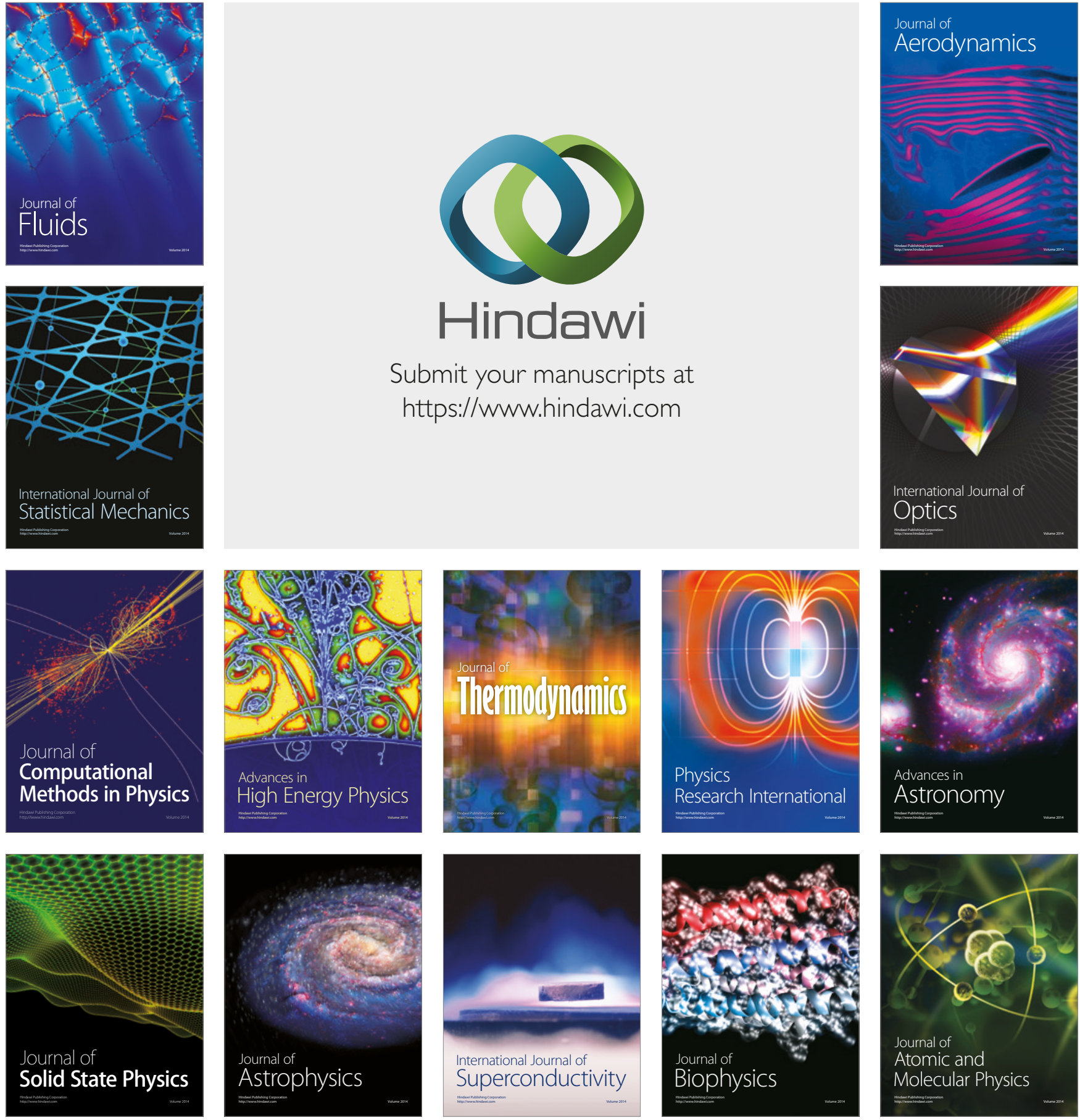